\title{
Óleo de andiroba: processo tradicional da extração, uso e aspectos sociais no estado do Amazonas, Brasil.
}

\author{
Andreza P. MENDONÇA ${ }^{1 *}$, Isolde Dorothea Kossmann FERRAZ²
}

\section{RESUMO}

O processo tradicional de extração do óleo das sementes de andiroba foi levantado em três municípios (Anamã, Manacapuru e Silves) no Estado do Amazonas. Em 1992 e 2004, foi aplicado um questionário a 38 extratoras. Sementes das duas espécies de andiroba (Carapa procera D.C. e Carapa guianensis Aubl.) foram utilizadas como matéria prima. O processo tradicional é complexo, demora cerca de dois meses e pode ser dividido em três etapas: 1 . A coleta, seleção de sementes boas e um primeiro armazenamento (3-15 dias). 2. O preparo da massa pelo cozimento das sementes em água (1-3 horas), um segundo período de armazenamento (até 20 dias) e finalizada pela retirada da casca e o amassamento das amêndoas. 3. A extração do óleo (até 30 dias), pelo gotejamento colocando a massa sobre uma superfície inclinada. Óleo extraído na sombra foi considerado de melhor qualidade do que no sol, porém o processo é mais demorado. Uma segunda extração com a prensa ("tipiti”), usada na fabricação de farinha, foi raramente empregada. Verificaram-se pequenas variaçōes entre os procedimentos das extratoras, aparentemente com conseqüências na rentabilidade e na qualidade do óleo. Na primeira e segunda etapa da extração participaram membros da família e/ou vizinhos, ao contrário da etapa final, realizada por uma única mulher. Enquanto, transmissão do conhecimento tradicional, em geral, costuma passar de geração por geração pela oralidade e observação, este estudo revelou, que os jovens não participam mais da extração. Fato, que no futuro próximo, pode causar a perda de conhecimento em relação à extração do óleo de andiroba pelo método tradicional.

\section{PALAVRAS-CHAVES}

Carapa procera D.C., Carapa guianensis Aubl., Conhecimento popular, Semente oleaginosa, Rendimento.

\section{Crapwood oil: traditional extraction, use and social aspects in the state of Amazonas, Brasil}

\begin{abstract}
The traditional method of oil extraction from crabwood seeds was observed in three municipalities (Anamã, Manacapuru e Silves) in the state of Amazonas. In 1992 and 2004 a total of 38 producers were interviewed. Seeds of two species (Carapa procera D.C. and Carapa guianensis Aubl.) were used for oil extraction. The complex process requires about two months and can be divided into three stages: 1 . seed collection by gathering and storing good seed (3-5 days). 2. "seed cake" preparation by cooking the seeds in boiling water (1-3 hours), followed by a second storage period (up to 20 days), completed by removing the seed coat and kneading the seed mass; 3 . Oil extraction (up to 30 days) by collecting the oil dripping from the "seed cake" placed on an inclined plate. Oil extracted in the shade was considered of better quality than in the sun, but the process needed more time. A second extraction with the press ("tipiti") used for manioc flour was rarely used. Comparing the methods of the producers, some minor variations were observed apparent consequences in yield as well as quality. The first and second stages of the process involved the collaboration of relatives and/or neighbors, whereas the last stage was executed by only one woman. Transmission of traditional knowledge is passed from generation to generation by orality and observation. This study revealed that young persons no longer participated. This may cause, in the near future a loss of knowledge and skill in performance for crabwood seed oil extraction by the traditional method.
\end{abstract}

\section{KEYWORDS}

Carapa procera D.C., Carapa guianensis Aubl., Popular knowledge, Oilseed, Yield.

1 Instituto Nacional de Pesquisas da Amazônia, Coordenação de Pesquisas em Silvicultura Tropical.. e-mail: ap_mendonca@click21.com.br. "Endereço para correspondência: Rua Rio Madeira, 487 - Adrianopólis. CEP: 69057-490. Manaus - AM.

2 Instituto Nacional de Pesquisas da Amazônia, Coordenação de Pesquisas em Silvicultura Tropical. Avenida André Araujo, 2936; Caixa Postal 478 - Aleixo. CEP. 69087-000 - Manaus, AM - Brasil. Telefone: (92) 36431839 Fax: (92) 36431836. e-mail: iferraz@inpa.gov.br 


\section{INTRODUÇÃO}

No estado do Amazonas, o nome andiroba é atribuído a duas espécies: Carapa guianensis Aubl. com ocorrência em toda a bacia Amazônica, preferencialmente em ambiente de várzea e Carapa procera D.C. espécie mais restrita a algumas áreas na Amazônia, porém com ocorrência também na África (Ferraz et al., 2002). A andiroba é de uso múltiplo: a madeira utilizada para fabricação de móveis, construção civil, lâminas e compensado e as sementes para extração de óleo. Ao longo da história do Amazonas o óleo de andiroba teve uma importante participação na economia regional e continua sendo muito apreciado, principalmente, na medicina popular. Em comparação com a exploração madeireira, a coleta das sementes necessita pouco investimento e, além de não ser destrutiva, a produção do óleo pode assegurar um retorno econômico anual para a população local. O óleo e seus subprodutos, tais como sabonetes e velas são geralmente encontrados em feiras livres. O óleo também tem sido comercializado para outras regiōes do país, além de ser exportado, principalmente, para indústria de cosméticos da França, Alemanha e dos Estados Unidos (Gonçalves, 2001).

O processo tradicional de extração do óleo de andiroba é longo e complexo. O isolamento geográfico das comunidades faz com que a divisão técnica e social do trabalho seja no geral, reduzida a uma família que domina todo o processo até o produto final. Até agora o conhecimento deste processo foi sempre transmitido pela oralidade pelos mais velhos. Porém, as mudanças sociais combinadas à praticidade e eficiência de outros métodos de extração do óleo, como a prensa, têm contribuído para perda do conhecimento do processo tradicional de extração do óleo em algumas comunidades. Entretanto, deve-se ressaltar que ainda há pessoas que realizam a extração tradicional, principalmente, em localidades isoladas, sem eletricidade, e com escassez de bens e serviços.

Na revisão das poucas informações escritas (Pesce, 1941, Aublet, 1977; Grenand et al., 1987, Shanley et al., 1998), foi verificado que não há relatos sobre o uso das duas espécies para extração do óleo. Foram verificadas ainda variaçôes nos procedimentos de extração e que as informações de rendimento variaram de cinco a $30 \mathrm{~kg}$ de sementes para um litro de óleo (Bahia apud Silva, 2004; Gonçalves, 2001). Assim os procedimentos de extração podem ter conseqüências tanto na rentabilidade quanto na qualidade do óleo.

Portanto, este trabalho teve como objetivos: fazer um levantamento dos processos de extração tradicional do óleo de andiroba realizados em três municípios no Estado do Amazonas, descrever detalhadamente os procedimentos e observar as variaçôes que possam afetar a rentabilidade do óleo. O estudo visa, desta forma, contribuir para a preservação do conhecimento tradicional e a comparação dos métodos, a fim de assegurar maior rentabilidade e melhor aproveitamento do recurso natural.

\section{MATERIAL E MÉTODOS}

O processo de extração do óleo de andiroba foi levantado em 1992 e em 2004 com aplicação de um questionário. O questionário abordou, desde a coleta e seleção das sementes, todos os procedimentos para extração do óleo até o acondicionamento do produto final. Visou também levantar os usos do óleo, dos resíduos e das demais partes das duas espécies de andiroba pelas extratoras. O questionário aplicado foi aprovado pela Comissão de Ética em Pesquisa da Fundação Centro de Controle de Oncologia da FCECON, no 0009/2003 (Tabela 1).

Em dezembro de 1992 foram consultadas 10 extratoras nas comunidades de Manacapuru: Lago do Paru $(n=2)$, São João (n=1), Costa do Marrecão $(n=4)$ e Bela Vista $(n=3)$ e em abril e maio de 2004 (época de frutificação da espécie) foram consultadas 28 extratoras nas comunidades de Manacapuru: Bela Vista ( $n=5)$, Lago do Castanho $(n=4)$ e Jaiteu $(n=4)$; Anamã: Paraná do Anamã ( $\mathrm{n}=2)$ e Cuiá $(\mathrm{n}=5)$ e Silves: Marupá ( $\mathrm{n}=1)$, Nossa Senhora de Aparecida $(\mathrm{n}=1)$, Nossa Senhora da Conceição $(\mathrm{n}=2)$ e São Tomé do Jacu $(\mathrm{n}=4)$. Esses municípios ficam de 69 a $180 \mathrm{~km}$ de distância da cidade de Manaus, porém o acesso às comunidades é exclusivamente por via fluvial, com exceção de Bela Vista no município de Manacapuru.

Foram realizadas também visitas aos locais de coleta das sementes de andiroba e identificada à espécie a partir das características morfológicas das sementes conforme Pennington et al. (1981) e Ferraz et al. (2002).

\section{RESULTADOS}

Nas comunidades de Manacapuru, Anamã e Silves, as duas espécies de andiroba foram usadas na extração do óleo. Não foi relatada nenhuma necessidade de diferenciar o procedimento $\mathrm{e}$, freqüentemente, as sementes das duas espécies foram misturadas. Às vezes, $C$. procera foi denominada de andirobabrava e C.guianensis de andiroba-mansa. A distinção entre as duas espécies foi, principalmente, pelo tamanho das sementes sem considerar outros caracteres morfológicos, o que não assegurou às extratoras a identificação correta das espécies. As visitas mostraram que a Carapa procera apresentou ocorrência natural na terra-firme e Carapa guianensis foi encontrada tanto na várzea como na terra-firme. Ambas as espécies foram também plantadas próximo às habitaçōes em áreas de várzea e terra-firme. Durante a coleta das sementes as extratoras observaram como predadores: cutia, paca, papagaio, porco do mato, curica, arara, veados, ratos, ovelha e boi (Tabela 2). 
Tabela 1 - Questionário aplicado às extratoras do óleo de andiroba nos municípios de Anamã, Manacapuru e Silves em 1992 e 2004, Amazonas.

\begin{tabular}{|c|c|}
\hline \multicolumn{2}{|l|}{$\begin{array}{l}\text { Comunidade: } \\
\text { Entrevistado:_ Município: } \_ \text {Dade: }\end{array}$} \\
\hline Com quem aprendeu & Método e extração da massa \\
\hline Quem da família sabe extrair & Aspecto da massa: no início / no final \\
\hline Coleta de sementes: & Tempo de extração \\
\hline Andiroba é: ( ) Nativa ( ) Plantada & Instrumentos usados \\
\hline Espaçamento ...........m & Amassar a massa (vezes / dia) \\
\hline Idade do plantio & Faz um rego / furo na massa \\
\hline ( ) Várzea ( ) Terra firme & ( ) sim ( ) não, detalhar \\
\hline ( ) C. guianensis ( ) C. procera & Quem ajuda no amassamento \\
\hline Como distinguir as duas andirobas & Local da extração: ( ) sol ( ) sombra \\
\hline Época da coleta & 0 óleo é recolhida diariamente ou fica no local \\
\hline Quem ajuda na coleta: & ( ) $\operatorname{sim}($ ) não \\
\hline Durante quanto tempo coleta:..........meses & Utiliza / conheça os métodos \\
\hline Quantas coletas por ano & ( ) tipiti \\
\hline Época de frutificação & ( ) sombra $=>$ sol \\
\hline Quais animais comem as sementes & ( ) sol => tipiti \\
\hline As sementes são armazenadas antes de cozinhar ( ) sim ( ) não & ( ) outro método, especificar \\
\hline Onde & Usa o resíduo: ( ) sim ( ) não \\
\hline Quanto tempo & Para quê \\
\hline Como & Refinamento do óleo \\
\hline Seleção das sementes & Utiliza algodão para filtrar ( ) sim ( ) não \\
\hline Coleta de sementes: ( ) copa da árvore ( ) solo & ( ) outro filtro; detalhar \\
\hline Todas as sementes podem ser coletadas & Onde acondiciona o óleo \\
\hline Como reconhece uma semente estragada & Por quanto tempo \\
\hline Semente germinada presta ( ) sim ( ) não & Usa o óleo para quê \\
\hline Cozimento & Existem diferentes qualidades de óleo \\
\hline Tempo de cozimento.......horas & ( ) sim ( ) não \\
\hline Tipo de fogo & Quais \\
\hline Recipiente utilizado & Como reconhece \\
\hline Ponto do cozimento & Rentabilidade \\
\hline Repouso & Quantos litros de óleo podem se obter de uma lata de sementes (18 \\
\hline As sementes são armazenadas após cozimento & litros) \\
\hline ( ) sim ( ) não & Qual espécie produz mais óleo: \\
\hline A casca é retirada antes do repouso & Comercialização do óleo \\
\hline ( ) $\operatorname{sim}($ ) não & Vende o óleo ( ) sim ( ) não \\
\hline Tempo do repouso & Onde \\
\hline Local do repouso & Para quem \\
\hline Usa forragem ( ) sim ( ) não. & Quem utiliza o seu óleo \\
\hline Usa forragem ( ) abaixo ( ) acima & Tem dificuldade para escoar a produção \\
\hline Qual tipo de forragem & Quer produzir mais óleo \\
\hline Preparo da massa & \\
\hline Ponto para fazer a massa & \\
\hline Instrumentos usados para quebrar as sementes e retirar as amêndoas & \\
\hline 0 que faz com as cascas & \\
\hline Aparecem fungos nas sementes / amêndoas & \\
\hline Como é feita a seleção das sementes para fazer a massa & \\
\hline Como a massa é amassada & \\
\hline Quem ajuda na preparação da massa & \\
\hline
\end{tabular}

As extratoras relataram que o boi além das sementes comiam o resíduo da extração do óleo de andiroba. O processo tradicional de extração do óleo de andiroba pode ser dividido em três etapas: Coleta e seleção das sementes (Tabela 2); Preparo da massa (Tabela 3) e a Extração do óleo (Tabela 4).

\section{COLETA, SELEÇÃO E ARMAZENAMENTO DAS SEMENTES}

Nos três municípios a época da frutificação de ambas espécies ocorre, normalmente entre abril e julho. Ao coletar as sementes abaixo das árvores, todas as extratoras realizaram uma primeira seleção e consideraram inadequadas: sementes brocadas (provavelmente infestadas pela Hypsipyla), ruídas 
por mamíferos, dessecadas e com cor da casca muito escura. Sementes germinadas com até dois centímetros de raiz foram consideradas adequadas pela metade das entrevistadas. Em seguida, as sementes adequadas foram armazenadas por um período de três a 15 dias, geralmente no assoalho das casas, sobre ou dentro de sacos de estopa. Na entrevista de 1992 o critério de seleção das sementes e o ambiente do armazenamento foi o mesmo, porém naquela época as sementes foram também guardadas dentro de caixas de madeira (Tabela 2).

Tabela 2 - Coleta, seleção e armazenamento das sementes, $1^{\text {a }}$. etapa do processo tradicional da extração do óleo de andiroba em três municípios do Estado do Amazonas

\begin{tabular}{|c|c|c|c|c|c|c|c|c|c|c|}
\hline \multirow{2}{*}{$\frac{.0}{\frac{0}{0}}$} & \multirow{2}{*}{ Comunidade } & \multirow{2}{*}{$\begin{array}{l}N^{0} \text { de } \\
\text { entre- } \\
\text { vistas }\end{array}$} & \multirow{2}{*}{ Carapa } & \multirow{2}{*}{ Habitat } & \multirow{2}{*}{$\begin{array}{l}\text { Procedência das } \\
\text { sementes }\end{array}$} & \multirow{2}{*}{$\begin{array}{l}\text { Época } \\
\text { coleta }\end{array}$} & \multirow{2}{*}{$\begin{array}{l}\text { Predadores } \\
\text { observados }\end{array}$} & \multirow{2}{*}{$\begin{array}{l}\text { Sementes } \\
\text { excluídas do } \\
\text { processo }\end{array}$} & \multicolumn{2}{|c|}{ Armazenamento das sementes } \\
\hline & & & & & & & & & Local & $\begin{array}{l}\text { Tempo } \\
\text { (dia) }\end{array}$ \\
\hline \multirow{4}{*}{ 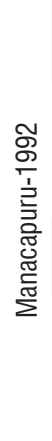 } & São João & 1 & guianensis & várzea & plantio & dez-mai & cutia & $\begin{array}{l}\text { germinadas, muito } \\
\text { escuras }\end{array}$ & assoalho da casa & $15-20$ \\
\hline & $\begin{array}{l}\text { Lago do } \\
\text { Paru }\end{array}$ & 2 & procera & $\begin{array}{l}\text { terra } \\
\text { firme }\end{array}$ & $\begin{array}{l}\text { plantio; } \\
\text { ocorrência } \\
\text { natural }\end{array}$ & jun & cutia & $\begin{array}{l}\text { furadas, } \\
\text { germinadas, muito } \\
\text { escuras }\end{array}$ & --- & --- \\
\hline & $\begin{array}{l}\text { Costa do } \\
\text { Marrecão }\end{array}$ & 4 & $\begin{array}{l}\text { guianensis } \\
\text { procera }\end{array}$ & várzea & plantio & abr-jun & rato & $\begin{array}{l}\text { furadas, leves, } \\
\text { germinadas }\end{array}$ & caixa de madeira & 15 \\
\hline & Bela Vista & 3 & $\begin{array}{l}\text { guianensis } \\
\text { procera }\end{array}$ & $\begin{array}{l}\text { terra } \\
\text { firme }\end{array}$ & plantio & mai-jun & $\begin{array}{l}\text { cutia,rato, } \\
\text { porco-do- } \\
\text { mato, paca, } \\
\text { papagaio }\end{array}$ & $\begin{array}{l}\text { furadas, leves, } \\
\text { germinadas }\end{array}$ & assoalho da casa & $10-15$ \\
\hline \multirow{3}{*}{ 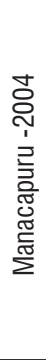 } & Bela Vista & 5 & guianensis & $\begin{array}{l}\text { terra } \\
\text { firme }\end{array}$ & $\begin{array}{l}\text { plantio } \\
\text { aleatório } \\
\text { (13 anos) }\end{array}$ & mai-jul & $\begin{array}{l}\text { cutia, pacas, } \\
\text { ratos }\end{array}$ & $\begin{array}{l}\text { furadas, ruídas, } \\
\text { leves, germinadas }\end{array}$ & $\begin{array}{l}\text { assoalho da casa } \\
\text { sobre saco de fibra } \\
\text { ou papelão }\end{array}$ & 10 \\
\hline & $\begin{array}{l}\text { Lago do } \\
\text { Castanho }\end{array}$ & 4 & $\begin{array}{l}\text { guianensis } \\
\text { procera }\end{array}$ & $\begin{array}{l}\text { terra } \\
\text { firme }\end{array}$ & $\begin{array}{l}\text { ambas } \\
\text { ocorrência } \\
\text { natural }\end{array}$ & $\begin{array}{l}\text { mar-mai } \\
\text { mai- jul }\end{array}$ & $\begin{array}{l}\text { boi, cutia, } \\
\text { paca, veado }\end{array}$ & $\begin{array}{l}\text { furadas, ruídas, } \\
\text { leves }\end{array}$ & $\begin{array}{l}\text { assoalho da casa } \\
\text { sobre saco de fibra } \\
\text { ou dentro de paneiro }\end{array}$ & 7 \\
\hline & Jaiteu & 4 & $\begin{array}{l}\text { guianensis } \\
\text { procera }\end{array}$ & $\begin{array}{l}\text { terra } \\
\text { firme }\end{array}$ & $\begin{array}{l}\text { ambas } \\
\text { ocorrência } \\
\text { natural }\end{array}$ & abr-jul & cutia, curica & $\begin{array}{l}\text { furadas, ruídas, } \\
\text { leves }\end{array}$ & $\begin{array}{l}\text { assoalho da casa } \\
\text { sobre saco de fibra } \\
\text { ou dentro de paneiro }\end{array}$ & $7-15$ \\
\hline \multirow{2}{*}{ 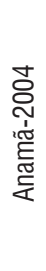 } & $\begin{array}{l}\text { Paraná do } \\
\text { Anamã }\end{array}$ & 2 & guianensis & várzea & $\begin{array}{l}\text { plantio } \\
5 \times 5 \mathrm{~m} \text { (28 anos); } \\
\text { ocorrência } \\
\text { natural }\end{array}$ & abr-jul & $\begin{array}{l}\text { cutia, pacas, } \\
\text { papagaio, } \\
\text { ovelha }\end{array}$ & $\begin{array}{l}\text { furadas, ruídas, } \\
\text { leves, germinadas }\end{array}$ & $\begin{array}{l}\text { assoalho da casa } \\
\text { sobre saco de fibras }\end{array}$ & 3 \\
\hline & Cuiá & 5 & guianensis & várzea & $\begin{array}{l}\text { plantio } 3 \times 3 \mathrm{~m}, \\
5 \times 5 \mathrm{~m}, 30 \times 30 \mathrm{~m} \\
(10 \text { a } 40 \text { anos) }\end{array}$ & mai-jul & $\begin{array}{l}\text { araras, } \\
\text { papagaios }\end{array}$ & $\begin{array}{l}\text { furadas, ruídas, } \\
\text { muito escuras }\end{array}$ & $\begin{array}{l}\text { na casa dentro de } \\
\text { saco de fibra }\end{array}$ & $3-10$ \\
\hline \multirow{4}{*}{ 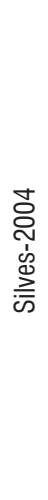 } & Marupá & 1 & guianensis & várzea & $\begin{array}{l}\text { plantio } \\
\text { aleatório } \\
\text { (90 anos) }\end{array}$ & mar-jun & boi & leve, furadas & $\begin{array}{l}\text { saco de fibra ou no } \\
\text { paneiro }\end{array}$ & 4 \\
\hline & $\begin{array}{l}\text { Nossa } \\
\text { Senhora de } \\
\text { Aparecida }\end{array}$ & 1 & guianensis & $\begin{array}{l}\text { terra } \\
\text { firme }\end{array}$ & $\begin{array}{l}\text { plantada } \\
\text { (55 anos) }\end{array}$ & $\begin{array}{l}\text { ago-set, } \\
\text { mai-jul }\end{array}$ & boi & leve, furadas & --- & 1 \\
\hline & $\begin{array}{l}\text { Nossa } \\
\text { Senhora da } \\
\text { Conceição }\end{array}$ & 2 & $\begin{array}{l}\text { guianensis } \\
\text { procera }\end{array}$ & $\begin{array}{l}\text { várzea } \\
\text { e terra } \\
\text { firme }\end{array}$ & $\begin{array}{l}\text { plantio: } 4 \times 4 \mathrm{~m}, \\
6 \times 6 \mathrm{~m} \text { (55 anos) }\end{array}$ & mai-jul & boi & leve, furadas & $\begin{array}{l}\text { assoalho da casa } \\
\text { sobre saco de fibra }\end{array}$ & 3 \\
\hline & $\begin{array}{l}\text { São Tomé } \\
\text { do Jacu }\end{array}$ & 4 & $\begin{array}{l}\text { guianensis } \\
\text { procera }\end{array}$ & $\begin{array}{l}\text { várzea } \\
\text { e terra } \\
\text { firme }\end{array}$ & $\begin{array}{l}\text { plantio aleatório } \\
\text { (13-70 anos); } \\
\text { ocorrência } \\
\text { natural }\end{array}$ & mai-jul & $\begin{array}{l}\text { cutia, paca, } \\
\text { papagaio }\end{array}$ & leve, furadas & $\begin{array}{l}\text { assoalho da casa, } \\
\text { saco de fibra, dentro } \\
\text { de canoa velha }\end{array}$ & $2-15$ \\
\hline
\end{tabular}




\section{PREPARO DA MASSA}

O segundo passo da extração do óleo de andiroba foi chamado pelas extratoras: preparo da "massa do pão". Essa atividade iniciou-se com o cozimento das sementes, geralmente, em latas de alumínio de 18 litros (reutilização de latas de tintas) ou panelas de alumínio, em fogo a lenha por tempo que variou de uma a três horas (Tabela 3). O ponto ideal do cozimento das sementes foi verificado, na maioria dos casos, com a quebra da casca de uma semente e pela percepção que a amêndoa estava mole ao apertá-la.
Em seguida, as sementes foram colocadas para esfriar em ambiente arejado e armazenadas novamente em local seco, na maioria dos casos, no assoalho das casas sobre ou dentro de sacos de estopa por um período de sete a 20 dias no máximo (Tabela 3). Este segundo armazenamento foi, geralmente, chamado de repouso. Apesar da variação do período do repouso, a maioria das extratoras indicou que o tempo ideal é de 15 dias, pois acreditam que após esse período as sementes estão no ponto ideal para fazer a massa. Conforme os relatos, apareceram normalmente fungos nas cascas das sementes em

Tabela 3 - Preparo da massa, 2a . etapa do processo tradicional da extração do óleo de andiroba em três municípios do Estado do Amazonas

\begin{tabular}{|c|c|c|c|c|c|c|c|c|c|}
\hline \multirow{2}{*}{$\frac{.0}{\frac{2}{0}}$} & \multirow[b]{2}{*}{ Comunidade } & \multicolumn{3}{|c|}{ Cozimento das sementes } & \multicolumn{3}{|c|}{ Repouso das sementes } & \multirow{2}{*}{$\begin{array}{l}\text { Instrumento } \\
\text { para quebrar } \\
\text { sementes }\end{array}$} & \multirow{2}{*}{$\begin{array}{l}\text { Uso da } \\
\text { casca } \\
\text { (resíduo) }\end{array}$} \\
\hline & & $\begin{array}{l}\text { Recipiente / } \\
\text { Tipo de fogo }\end{array}$ & $\begin{array}{l}\text { Tempo de } \\
\text { cozimento } \\
\text { (horas) }\end{array}$ & $\begin{array}{l}\text { Final do } \\
\text { cozimento }\end{array}$ & Local / Condições & $\begin{array}{l}\text { Tempo } \\
\text { (dias) }\end{array}$ & $\begin{array}{l}\text { Final do } \\
\text { repouso }\end{array}$ & & \\
\hline \multirow{4}{*}{ 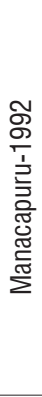 } & São João & $\begin{array}{l}\text { panela de alumínio / } \\
\text { fogo a lenha }\end{array}$ & 1 & amêndoa mole & assoalho da casa & 15 & $\begin{array}{l}\text { tempo pré- } \\
\text { determinado }\end{array}$ & faca & --- \\
\hline & $\begin{array}{l}\text { Lago do } \\
\text { Paru }\end{array}$ & $\begin{array}{l}\text { panela de alumínio / } \\
\text { fogo a lenha }\end{array}$ & 2 & casca escura & $\begin{array}{l}\text { casa / dentro de caixa de } \\
\text { madeira }\end{array}$ & --- & $\begin{array}{l}\text { quando começa } \\
\text { a sair óleo da } \\
\text { amêndoa }\end{array}$ & pedaço de pau & --- \\
\hline & $\begin{array}{l}\text { Costa } \\
\text { Marecão }\end{array}$ & $\begin{array}{l}\text { panela de alumínio } \\
\text { ou lata de } 18 \text { litros / } \\
\text { fogo a lenha }\end{array}$ & $2-3$ & amêndoa mole & $\begin{array}{l}\text { casa / dentro de caixa de } \\
\text { madeira }\end{array}$ & $15-30$ & $\begin{array}{l}\text { quando começa } \\
\text { a sair óleo da } \\
\text { amêndoa }\end{array}$ & $\begin{array}{l}\text { faca ou pedaço } \\
\text { de pau }\end{array}$ & -- \\
\hline & Bela Vista & $\begin{array}{l}\text { lata de } 18 \text { litros / } \\
\text { fogo a lenha }\end{array}$ & 0,5 & amêndoa mole & $\begin{array}{l}\text { assoalho da casa / sobre } \\
\text { folhas de bananeira ou } \\
\text { plástico }\end{array}$ & $15-20$ & $\begin{array}{l}\text { quando começa } \\
\text { a sair óleo da } \\
\text { amêndoa }\end{array}$ & $\begin{array}{l}\text { faca ou pedaço } \\
\text { de pau }\end{array}$ & --- \\
\hline \multirow{3}{*}{ 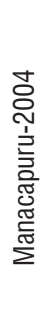 } & Bela Vista & $\begin{array}{l}\text { panelas de alumínio } \\
\text { ou lata de } 18 \text { litros / } \\
\text { fogo a lenha }\end{array}$ & $1-3$ & $\begin{array}{l}\text { amêndoa mole; } \\
\text { casca escura }\end{array}$ & $\begin{array}{l}\text { casa / dentro de saco de } \\
\text { fibra }\end{array}$ & $7-20$ & $\begin{array}{l}\text { tempo pré- } \\
\text { determinado }\end{array}$ & $\begin{array}{l}\text { faca ou pedaço } \\
\text { de pau }\end{array}$ & $\begin{array}{l}\text { queimar ou } \\
\text { descartar }\end{array}$ \\
\hline & $\begin{array}{l}\text { Lago do } \\
\text { Castanho }\end{array}$ & $\begin{array}{l}\text { panelas de alumínio } \\
\text { ou lata de } 18 \text { litros / } \\
\text { fogo a lenha }\end{array}$ & $1-2$ & amêndoa mole & $\begin{array}{l}\text { casa / dentro de saco } \\
\text { de fibra ou sobre o piso } \\
\text { coberto por saco }\end{array}$ & $7-20$ & $\begin{array}{l}\text { tempo pré- } \\
\text { determinado }\end{array}$ & $\begin{array}{l}\text { faca ou pedaço } \\
\text { de pau }\end{array}$ & descartar \\
\hline & Jaiteu & $\begin{array}{l}\text { panelas de alumínio } \\
\text { ou lata de } 18 \text { litros / } \\
\text { fogo a lenha }\end{array}$ & $1-2$ & amêndoa mole & $\begin{array}{l}\text { casa / dentro de saco } \\
\text { de fibra ou sobre o piso } \\
\text { coberto por saco }\end{array}$ & $7-15$ & $\begin{array}{l}\text { tempo pré- } \\
\text { determinado }\end{array}$ & $\begin{array}{l}\text { faca ou pedaço } \\
\text { de pau }\end{array}$ & descartar \\
\hline \multirow{2}{*}{ 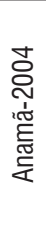 } & $\begin{array}{l}\text { Paraná do } \\
\text { Anamã }\end{array}$ & $\begin{array}{l}\text { panelas de alumínio } \\
\text { ou lata de } 18 \text { litros / } \\
\text { fogo a lenha }\end{array}$ & $0,5-1$ & amêndoa mole & $\begin{array}{l}\text { casa / dentro de saco } \\
\text { de fibra ou sobre o piso } \\
\text { coberto por saco }\end{array}$ & 15 & $\begin{array}{l}\text { tempo pré- } \\
\text { determinado }\end{array}$ & $\begin{array}{l}\text { faca ou pedaço } \\
\text { de pau }\end{array}$ & $\begin{array}{l}\text { queimar ou } \\
\text { descartar }\end{array}$ \\
\hline & Cuiá & $\begin{array}{l}\text { panelas de alumínio } \\
\text { ou lata de } 18 \text { litros / } \\
\text { fogo a lenha }\end{array}$ & $1-3$ & amêndoa mole & $\begin{array}{l}\text { casa / dentro de saco de } \\
\text { fibra ou sobre peneira }\end{array}$ & $8-15$ & $\begin{array}{l}\text { tempo pré- } \\
\text { determinado }\end{array}$ & $\begin{array}{l}\text { faca ou pedaço } \\
\text { de pau }\end{array}$ & $\begin{array}{l}\text { queimar ou } \\
\text { descartar }\end{array}$ \\
\hline \multirow{4}{*}{ 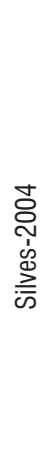 } & Marupá & $\begin{array}{l}\text { lata de } 18 \text { litros, } \\
\text { tacho de cobre / fogo } \\
\text { a lenha }\end{array}$ & 1 & amêndoa mole & casa / sobre peneira & 15 & $\begin{array}{l}\text { quando começa } \\
\text { a sair óleo da } \\
\text { amêndoa }\end{array}$ & pedaço de pau & $\begin{array}{l}\text { queimar ou } \\
\text { descartar }\end{array}$ \\
\hline & $\begin{array}{l}\text { Nossa } \\
\text { Senhora de } \\
\text { Aparecida }\end{array}$ & $\begin{array}{l}\text { lata de } 18 \text { litros / } \\
\text { fogo a lenha }\end{array}$ & 1 & amêndoa mole & $\begin{array}{l}\text { casa / dentro de saco de } \\
\text { fibra }\end{array}$ & 15 & $\begin{array}{l}\text { quando começa } \\
\text { a sair óleo da } \\
\text { amêndoa }\end{array}$ & faca & descartar \\
\hline & $\begin{array}{l}\text { Nossa } \\
\text { Senhora da } \\
\text { Conceição }\end{array}$ & $\begin{array}{l}\text { lata de } 18 \text { litros / } \\
\text { fogo a lenha }\end{array}$ & $0,3-1$ & amêndoa mole & $\begin{array}{l}\text { casa / sobre peneira } \\
\text { coberto com folha de } \\
\text { bananeira, sobre o piso } \\
\text { coberto por saco }\end{array}$ & $8-17$ & $\begin{array}{l}\text { quando começa } \\
\text { a sair óleo da } \\
\text { amêndoa }\end{array}$ & $\begin{array}{l}\text { pedaço de pau } \\
\text { ou faca }\end{array}$ & descartar \\
\hline & $\begin{array}{l}\text { São Tomé do } \\
\text { Jacu }\end{array}$ & $\begin{array}{l}\text { lata de } 18 \text { litros / } \\
\text { fogo a lenha }\end{array}$ & 1 & amêndoa mole & $\begin{array}{l}\text { casa / sobre peneira, } \\
\text { dentro saco de fibra }\end{array}$ & $12-15$ & $\begin{array}{l}\text { tempo pré- } \\
\text { determinado }\end{array}$ & faca & $\begin{array}{l}\text { queimar ou } \\
\text { descartar }\end{array}$ \\
\hline
\end{tabular}


repouso. No geral, o final do repouso foi verificado, quebrando a casca da semente e, ao apertar a amêndoa, perceber a liberação do óleo. Somente uma extratora em Bela Vista não deixou as sementes em repouso e preparou imediatamente a massa após cozimento.

Após o repouso, as cascas das sementes foram quebradas por meio de um pedaço de pau ou as mesmas foram cortadas com faca para a retirada da amêndoa, com auxílio do cabo de uma colher. As amêndoas com cor muito escura foram consideradas inadequadas para extração do óleo. As amêndoas adequadas foram amassadas com as mãos formando a massa para extração do óleo (Tabela 3).

Em 1992 as sementes foram repousadas sobre folhas de bananeira em lugares similares aos descritos pelas extratoras em 2004. Observou-se também que as amêndoas após retiradas das cascas foram piladas, enquanto que em 2004 as amêndoas foram somente amassadas com as mãos. Os demais procedimentos para o preparo da massa foram os mesmos (Tabela 3).

\section{EXTRAÇÃO DO ÓLEO}

O último passo da extração do óleo foi realizado de várias formas: ao sol, a sombra ou ainda com o Tipiti (prensa típica da Amazônia feita de palha de forma cilíndrica, confeccionada para suportar extensão, possui uma abertura na parte superior com uma alça e está fechada na parte inferior com duas alças, ao ser estendida, a prensa diminui o seu volume e comprime o seu conteúdo) (Tabela 4).

Nos métodos de extração ao sol ou a sombra, a massa, de cerca de 3 a $4 \mathrm{~kg}$, em forma globosa oblonga foi colocada

Tabela 4 - Extração do óleo de andiroba, $3^{\text {a }}$. etapa do processo tradicional em três municípios do Estado do Amazonas.

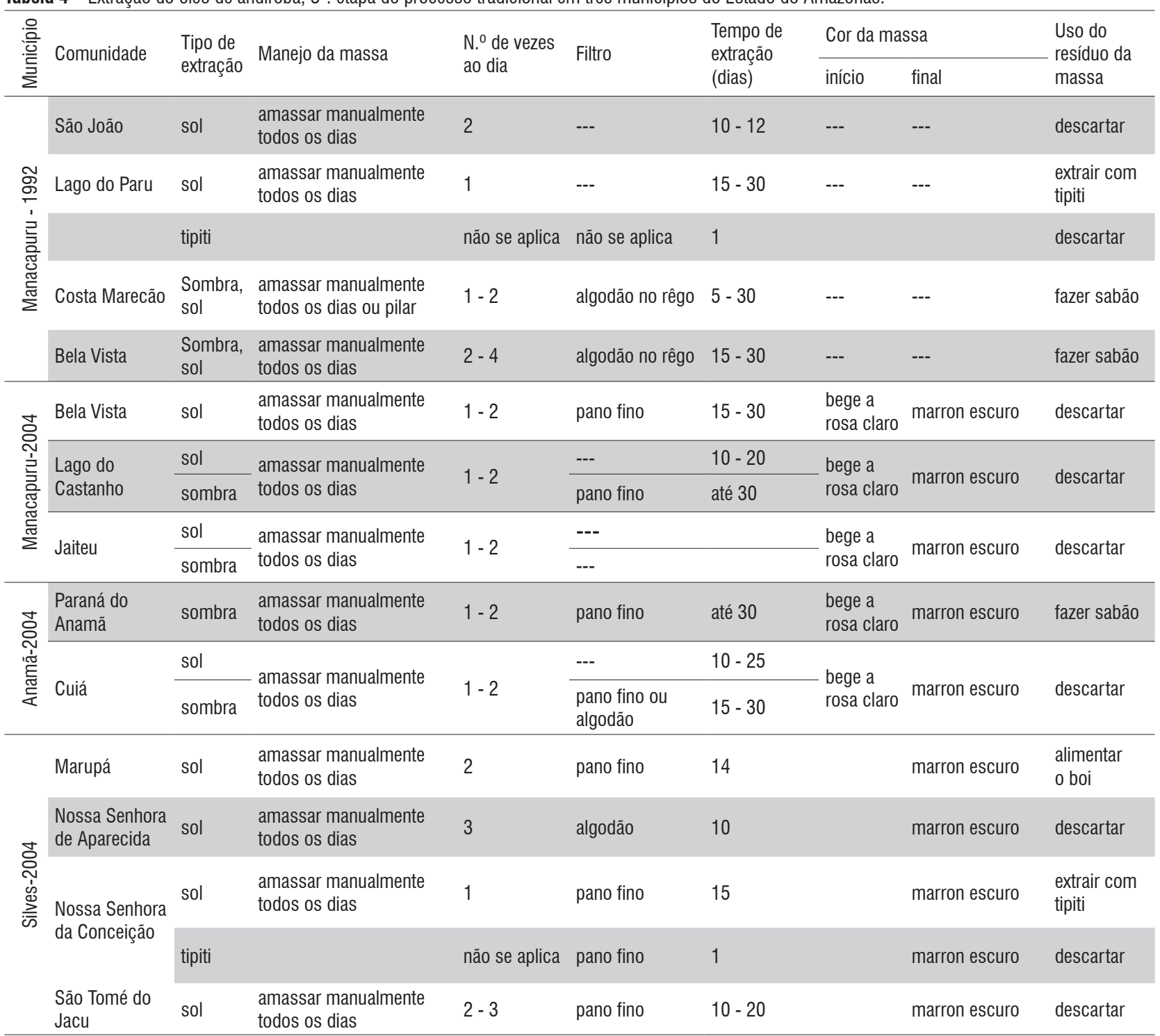


sobre uma superfície inclinada (pedaços de alumínio ou bacias de alumínio), a fim de recolher o óleo liberado. Em 1992 observou-se que algumas extratoras fizeram um furo longitudinal na massa para facilitar a liberação do óleo, enquanto, a maioria das extratoras em 2004 imprimiu um rego longitudinal no meio da massa.

Diariamente, a massa foi amassada com as mãos, no geral duas vezes, pela manhã e no início da tarde. As extratoras relataram que, às vezes, aparecem fungos na massa, que segundo elas não afetam na qualidade do óleo. A massa de andiroba no início da extração do óleo teve cor bege a rosa claro e no final da extração apresentou uma cor marrom que ao ser amassada esfarelou nas mãos. Após extração ao sol, uma entrevistada da comunidade de Nossa Senhora da Conceição em Silves, usou o tipiti para extrair mais óleo da massa. O processo de extração ao sol ocorreu durante um período médio de 15 a 25 dias, sendo mais rápido do que na sombra, com duração de até 30 dias (Tabela 4). As extratoras consideram o óleo extraído à sombra de melhor qualidade, mais "limpo", pois apresenta uma cor amarela clara semelhante ao óleo de cozinha, enquanto o óleo extraído ao sol é mais escuro.

\section{RECOLHIMENTO E ACONDICIONAMENTO DO ÓLEO EXTRAÍDO}

No final do processo, o óleo recolhido foi, geralmente, passado por um pano fino ou pedaço de algodão, processo chamado "filtragem" (Tabela 4). Apenas as extratoras das comunidades do Cuia e Nossa Senhora de Aparecida "filtraram" o óleo durante o processo de extração, colocando um pequeno pedaço de pano fino ou algodão no rêgo feito na massa. O óleo de andiroba foi acondicionado, principalmente, em garrafas de vidro transparentes $(965 \mathrm{ml}$, reutilizadas de cachaças) ou de plástico ( $600 \mathrm{ml}$ ou de dois litros), reutilizadas de água ou refrigerante. Segundo as extratoras, o óleo extraído ao sol solidifica, muitas vezes, no fundo da garrafa após um a seis meses.

\section{RENTABILIDADE DAS SEMENTES DE ANDIROBA PARA PRODUÇÃO DO ÓLEO}

As medidas de referência para as extratoras foram "uma lata" e "um litro". A "lata" foi reutilizada de tinta com volume de 181 e o "litro" o conteúdo de uma garrafa de cachaça com volume de $965 \mathrm{ml}$. As informações sobre a rentabilidade foram avaliadas apenas com as extratoras que tinham noção dessas medidas. Foi verificado que o peso de uma lata cheia de sementes possui cerca de $11 \mathrm{~kg}$ e contém, em média, 700 a 800 sementes de $C$. procera, ou 450 a 500 sementes de $C$. guianensis. Às vezes, as sementes das duas espécies foram misturadas para extração do óleo. As extratoras atribuíram para a andiroba-mansa (C. guianensis) maior rendimento do que para a andiroba-brava (C. procera).

Segundo os relatos, as extratoras podem extrair de um a cinco litros de óleo de uma lata cheia de sementes. Foi elaborado um fluxograma do processo de extração tradicional do óleo de andiroba (Figura 1), no qual foram indicados os procedimentos em comuns relatados pelas extratoras. No mesmo fluxograma foram também indicadas, em caixas pontilhadas, variações nos procedimentos que eventualmente podem afetar o rendimento do óleo. Avaliando o tempo de antes e após o cozimento das sementes, observou-se que as extratoras que obtiveram somente um litro armazenaram as sementes de andiroba após a coleta de dois a 15 dias e as sementes cozidas de sete a 20 dias, enquanto que as extratoras

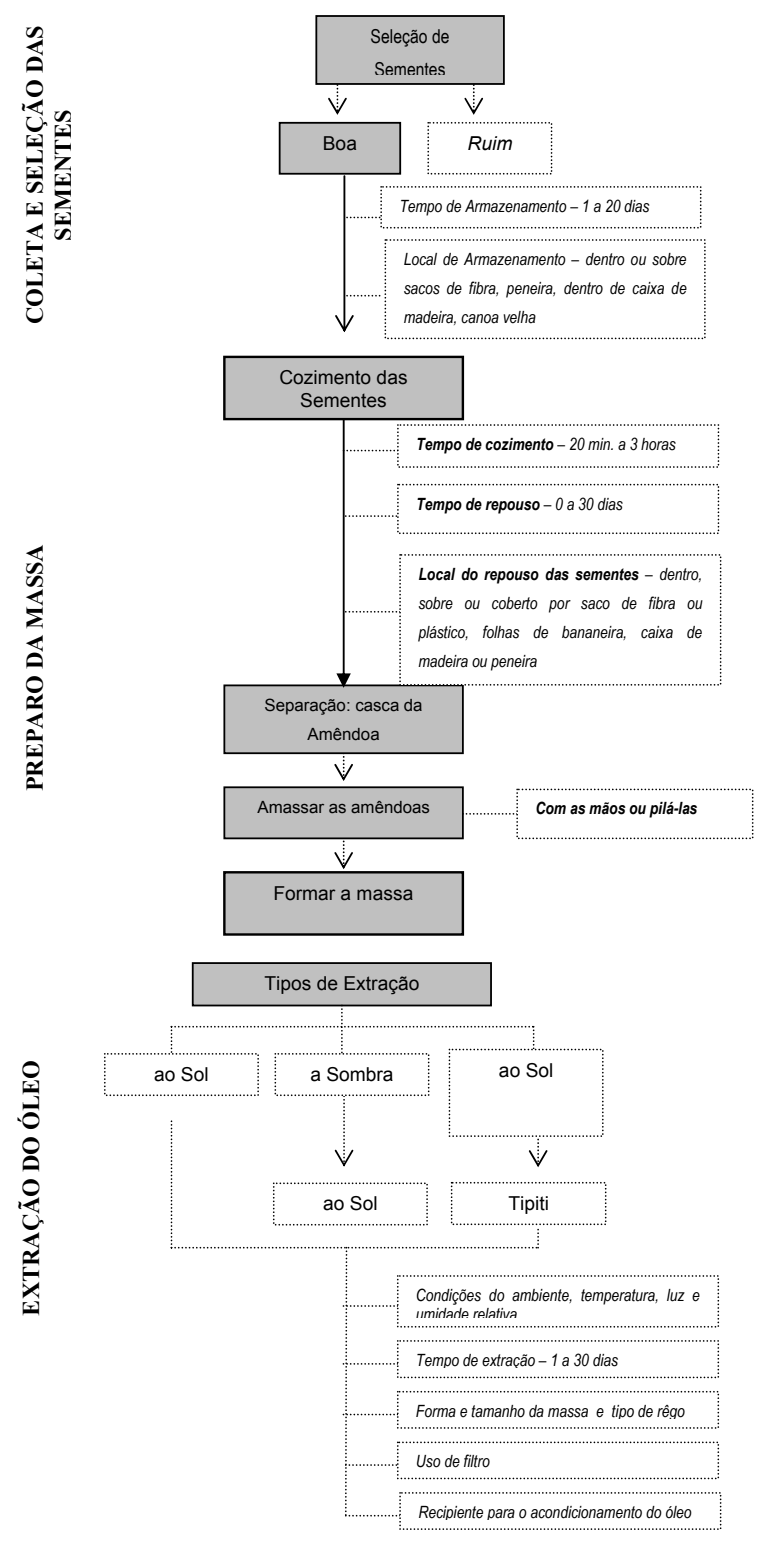

Figura 1 - Fluxograma do procedimento tradicional de extração do óleo de andiroba das extratoras dos municípios de Manacapuru, Anamã e Silves em 1992 e 2004. As caixas pontilhadas indicam as variações encontradas e outros fatores que podem influenciar a quantidade e/ou qualidade do óleo. 
que extraíram cinco litros armazenaram as sementes após a coleta por somente dois dias e as sementes cozidas pelo menos 15 dias (Figura 2). Portanto, esse manejo das sementes pode ser um fator que afeta a rentabilidade do óleo. De outro lado, as extratoras apresentaram algumas crenças relacionadas ao rendimento do óleo (ver aspectos sociais), que provavelmente inibem a troca de experiências e o aprimoramento do processo.

\section{USO DO ÓLEO E DOS RESÍDUOS}

O uso externo do óleo de andiroba foi indicado pelas comunitárias como repelente, contra parasitas (piolhos) e coceiras em geral, como cicatrizante de ferimentos e para retirar carne crescida dos olhos. O uso interno foi, principalmente, recomendado para combater gripe, febre, asma, dor na garganta e até mesmo para baixar o nível de glicose no sangue (diabetes). Uma comunitária do São Tomé do Jacu usa o óleo de andiroba misturado com sal para evitar carrapato no gado.

O processo de extração deixa dois resíduos: as cascas das sementes após o repouso e a massa após o encerramento do recolhimento do óleo. Algumas extratoras queimam as cascas para afastar mosquitos (Tabela 3). O resíduo da massa foi aproveitado na fabricação caseira de sabão de andiroba em 1992 por quatro extratoras de Manacapuru e em 2004 somente por uma extratora da comunidade do Paraná do Anamã. Uma extratora de Silves deu a massa para o gado comer (Tabela 4).

\section{ASPECTOS SOCIAIS}

A extração do óleo de andiroba é uma atividade social que envolve em determinadas etapas, tais como a coleta das sementes e separação da casca da amêndoa membros da família e/ou vizinhos, por exemplo, nas comunidades de Bela Vista e Jaiteu (Manacapuru); Cuia (Anamã) e São Tomé do Jacu (Silves). Por outro lado, a fase da extração do óleo de andiroba foi realizada geralmente apenas por uma mulher. As extratoras acreditam que pessoas invejosas, mulheres grávidas ou menstruadas não podem ver, nem tocar a massa, pois cessaria a liberação do óleo. Em geral, notou-se que a atividade foi executada por mulheres casadas, acima de 35 anos e as jovens não tinham interesse em aprender o processo de extração. Assim, devido às mudanças sociais atuais e à transmissão do conhecimento pela observação e oralidade, prevê-se, no futuro próximo, que o conhecimento tradicional se perca.

Neste estudo observou-se que o comércio do óleo de andiroba foi maior nas comunidades de Silves em relação a Anamã e Manacapuru, possivelmente, devido a Associação Avive. Esta associação de mulheres, produtores de sabonetes e outros subprodutos com essências da Amazônia, compra o óleo das extratoras e vende os produtos em uma loja própria em Silves.

Nas comunidades de Manacapuru e Anamã as extratoras relataram que o comércio do óleo de andiroba é desestimulado devido ao baixo preço pago pelo óleo e a dificuldade de escoar a produção. $\mathrm{O}$ isolamento, principalmente em Anamã, perpetua a figura do atravessador.

Por outro lado, a colaboração durante a extração do óleo teve um papel social importante na consolidação da união comunitária. Além disso, o óleo presenteado às pessoas próximas e enviado aos parentes e amigos em Manaus, onde há melhor infra-estrutura em termos de atendimento médico e hospitalar, assegura os bons relacionamentos.

\section{DISCUSSÃO}

\section{PROCESSO TRADICIONAL DE EXTRAÇÃO DO ÓLEO}

Já em 1775, Aublet (1977) inclui na descrição da espécie de Carapa guianensis algumas informações sobre a extração do óleo, e mencionou duas tribos indígenas da Guiana Francesa, os Garipons que denominaram a árvore de Y-andiroba e os Galibis que deram o nome de Carapa. Outros autores relataram sobre o processo de extração do óleo de andiroba, porém todos se referem apenas a espécie C. guianensis: Pesce (1941) no Pará, Grenand et al. (1987) na Guiana Francesa com os índios Wayãpi e Shanley et al. (1998) no baixo rio Tocantins ao longos dos rios Capim e Guamá. As etapas básicas foram mencionadas por estes autores, entretanto pouca atenção foi dada aos detalhes do processo.

O cozimento das sementes na água foi mencionado por Aublet, (1775; 1977) e Pesce (1941); Grenand et al. (1987) acrescentaram a necessidade do cozimento por várias horas e Shanley et al. (1998) relataram que as sementes foram fervidas até amolecer. Neste estudo, houve a necessidade de cozimento de 1 a 3 horas até o amolecimento da amêndoa, verificada pela retirada de uma semente e quebra da sua casca. Uma maceração de dois dias, após o cozimento em água, foi mencionada somente por Pesce (1941), este procedimento foi desconhecido pelas entrevistadas no Amazonas. Na literatura há omissão da seleção prévia das sementes com a exclusão das sementes dessecadas, brocada e germinadas além de um armazenamento antes do cozimento.

De outro lado, o armazenamento das sementes após o cozimento foi relatado por todos os autores, porém houve diferença no tempo de repouso: as sementes foram amontoadas por alguns dias (Aublet, 1977), por vários dias (Grenand et al.,1987), deixando apodrecer por 8-10 dias (Pesce, 1941) ou por 40 dias empilhadas no chão e cobertas por folhas verdes (Shanley et al, 1998). Os relatos da literatura não mencionaram como o período de repouso foi determinado, enquanto neste estudo um terço das entrevistadas relataram 
que o final do repouso foi indicado quando a amêndoa liberou óleo ao ser apertada. Aparentemente, ocorrem alterações ao nível de parede ou membrana celular que possibilitam, após um certo tempo, a liberação do óleo. Estas observações podem nortear estudos futuros, a fim de aperfeiçoar o manejo das sementes sobre o rendimento, pois os resultados deste estudo indicaram que o maior rendimento foi alcançado quando o armazenamento antes do cozimento foi curto (0 a 2 dias) e longo (15 dias) após o cozimento (Figura 2).

Em todas as fontes como neste estudo as amêndoas foram separadas das cascas após o armazenamento das sementes cozidas. Em seguida, as amêndoas foram raladas sobre uma pedra ou piladas em pilão de madeira (Aublet, 1775 (1977)) ou amassadas (Pesce, 1941;Grenand et al., 1987). No Amazonas uma extratora utilizou pilão em 1992, que não foi mais observado em 2004. Os demais amassaram manualmente a massa.

A extração ao sol e a sombra também foram relatadas na literatura. Aublet (1977) menciona em 1775 que a tribo Galibis expôs a massa ao pleno sol sobre uma pedra inclinada, em forma de calha. Este autor observou também em outras habitaçôes o uso da prensa tipiti. Pesce (1941) descreve apenas que no Pará a massa foi colocada sobre pedaços de tábua ou canoa velha, ambas inclinadas expostas ao sol e quando a massa ficava dura era colocada dentro de um tipiti para extrair o restante de óleo. Grenand et al. (1987) observou nos Wayãpi o uso de folhas de palmeira inclinadas e expostas ao sol para receber a massa. No período de chuva a massa era coberta e, para liberar mais óleo era colocada próximo ao fogo. No Tocantins, a massa recebeu forma de bolinhas (sem informar o tamanho), que foram colocadas sobre superfície inclinada, tais como: cocho feito de pedaço de metal, canoa velha ou pedaço de madeira. Foi relatado que a massa das bolinhas após 4 a 6 dias, ficou dura e seca e para extrair mais óleo a massa foi exposta ao sol e, em seguida, colocada em um tipiti para extrair o restante do óleo. (Shanley et al., 1998). Aparentemente as bolinhas foram menores do que a massa utilizada neste estudo (cerca de 3 a $4 \mathrm{~kg}$ ), o que provavelmente reduziu o tempo de extração. Não há informaçôes na literatura sobre a necessidade de um amassamento diário e a impressão de um rego ou furo na massa como verificado neste estudo.

Nos diversos processos descritos na literatura a extração foi realizada em seqüência: a sombra e/ou ao sol e no final com o tipiti ou expondo a massa a calor extra, a fim de aumentar o rendimento. Todas as extratoras deste estudo conheciam a possibilidade de extrair mais óleo com tipiti, mas somente uma extratora em 1992, município de Manacapuru, e outra em 2004, município de Silves, utilizaram o tipiti.

Neste estudo como em outro realizado na Flona do Tapajós (Gonçalves, 2001) observou-se que as extratoras avaliaram a qualidade do óleo, principalmente, pelo odor, pela cor e pela consistência. No baixo Tocantins, Shanley et al. (1998) reportaram que o óleo da sombra foi chamado "óleo virgem" e foi também considerado mais "limpo" do que o extraído ao sol. Deve-se ressaltar que esse tipo de avaliação contribui para o uso irregular de recipientes transparentes, em lugar de vidro âmbar que conserva melhor as propriedades físicas e químicas do óleo vegetal. Este e outros fatores de acondicionamento inadequado como recipientes de volume maior do que a quantidade de óleo e embalagens plásticas permite maior contato do óleo com o ar e podem acelerar a sua oxidação.

\section{RENTABILIDADE DAS SEMENTES DE ANDIROBA PARA PRODUÇÃO DO ÓLEO}

$\mathrm{O}$ rendimento mencionado pelas extratoras neste estudo de 2 a $11 \mathrm{~kg}$ de sementes para um litro de óleo foi maior do que os $30 \mathrm{~kg}$ e $27 \mathrm{~kg}$ sementes em outros estudos (Salgado apud Silva, 2004, Gonçalves, 2001), porém similares aos $5 \mathrm{~kg}$ mencionados por (Bahia apud Silva, 2004). Pesce (1941) não quantificou o óleo em relação às sementes, porém relatou que
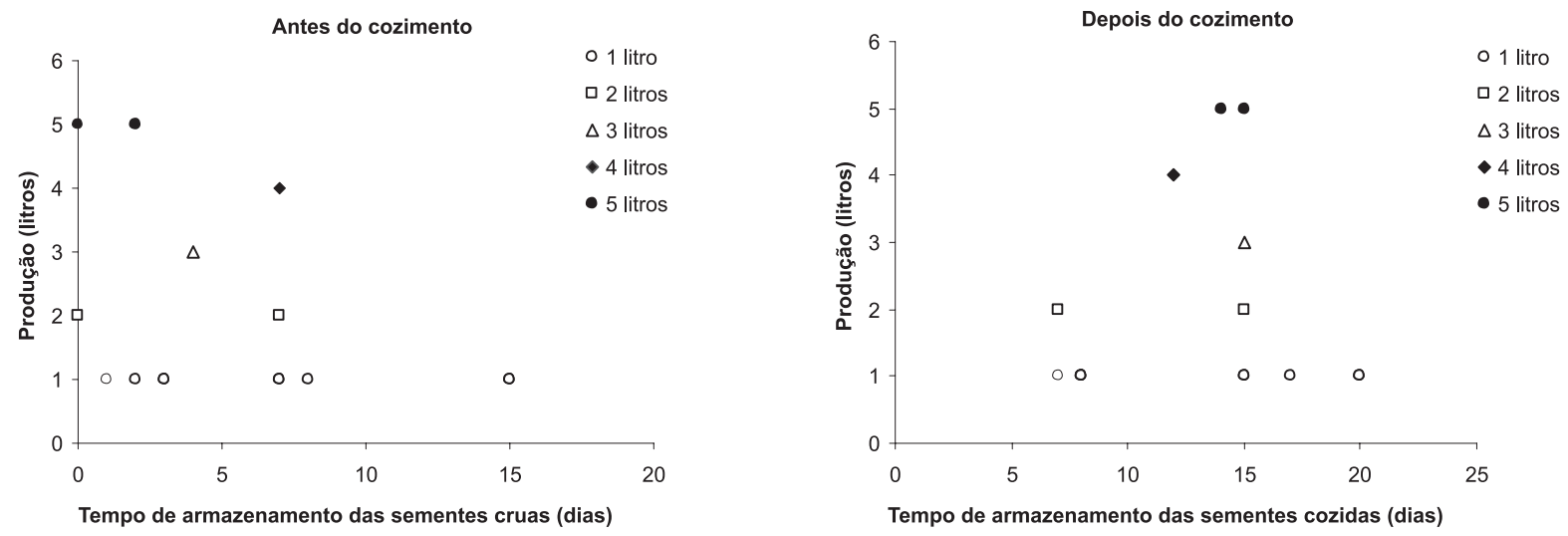

Figura 2 - Relação entre tempo de armazenamento das sementes de andiroba antes e após o cozimento e a quantidade de óleo extraído de cerca de 11 kg de sementes (uma lata de 18 I) conforme relatos das extratoras dos três municípios do Estado do Amazonas. 
a extração tradicional conseguiu extrair menos da metade do óleo contido nas sementes. Passando a massa seca novamente em prensa hidráulica conseguiu aumentar a quantidade de óleo em 25 a 30\%. Mencionou ainda que em geral o óleo produzido por escorrimento é liquido e o óleo obtido com o tipiti é sólido.

Em escala experimental a $C$. procera mostrou maior rendimento de óleo (cerca de $8 \mathrm{~kg}$ de sementes/ litro de óleo) em relação a $C$. guianensis (cerca de $11 \mathrm{~kg} / \mathrm{l}$ ) (Mendonça \& Ferraz, 2006). Estes resultados foram similares aos relatos das extratoras do Amazonas, porém contradisseram que $C$. guianensis rende mais do que $C$. procera. Possivelmente, as extratoras levaram mais em conta o esforço de coleta do que a medida de peso, pois as sementes da $C$. procera são menores. Assim para $11 \mathrm{~kg}$ são necessários de 700 a 800 sementes da $C$. procera e somente de 450 a 500 de sementes da $C$. guianensis.

A discrepância nos relatos de rendimento de $30 \mathrm{~kg}$ de sementes (Salgado apud Silva, 2004) a $2 \mathrm{~kg}$ (este estudo) para um litro de óleo, pode ser causada pelas variaçóes nos procedimentos de extração, em especial ao armazenamento antes e após o cozimento das sementes (Figura 2).

\section{USO DO ÓLEO E DOS RESÍDUOS}

O uso do óleo no Amazonas não diferiu dos relatos em outras localidades. Nas comunidades da reserva de Mamirauá, o óleo de andiroba foi usado para tratar escabiose (curuba), traumatismos, aliviar as dores no pescoço (torcicolo) e tirar carne crescida dos olhos (Souza et al., 2003). Os indígenas da Guiana Francesa utilizavam o óleo de andiroba misturado ao urucu como repelente de mosquito e pulgas dos pés (Pesce, 1941) e segundo Aublet (1977) impregnaram o corpo inteiro, inclusive os cabelos com o óleo. Também foi descrito o emprego contra distensões musculares e demais alterações cutâneas, em lamparinas para iluminação de casa e ainda para preparação de sabonetes e velas (Clay et al., 2000; Ferraz et al., 2002)

No Panamá as sementes de andiroba foram consideradas uma fonte de alimento primário para roedores, tatus, porcosdo-mato, pacas, veados e cutias (McHargue \& Hartshon, 1983). Neste estudo as sementes e/ou o resíduo da extração do óleo foram utilizados por cinco extratoras como alimento para animais domésticos, o boi e a ovelha. Apesar de Pesce (1941) menciona explicitamente que o farelo do resíduo não pode ser consumido pelo gado; as observações aqui apresentadas apontam a necessidade de uma nova avaliação sobre o uso dos resíduos como suplemento da ração.

\section{ASPECTOS SOCIAIS}

Tanto neste estudo como no de Gonçalves (2001) foram observadas divisões de trabalho durante o procedimento de extração. Na Floresta Nacional do Tapajós, a coleta e o transporte dos frutos e sementes de andiroba foram de responsabilidade masculina, enquanto a extração das sementes dos frutos e todos processos ligados a extração do óleo de responsabilidade feminina (Gonçalves, 2001). A restrição da última etapa do processo de extração a uma única mulher deve-se possivelmente a crenças relacionadas ao rendimento e, tem como conseqüência, uma restrição na transmissão do conhecimento e na troca de experiência, que por sua vez pode aumentar a variação do processo. Não há descrição na literatura sobre a importância social da produção do óleo para as comunidades isoladas. Neste estudo verificou-se que o envio do óleo possibilitou as interioranas manter o contato com parentes e amigos na capital.

\section{CONCLUSÃO}

O processo de extração pode ser dividido em três grandes etapas: coleta e seleção das sementes, preparação da massa e extração do óleo. As comunitárias usaram para a extração do óleo de andiroba sementes das duas espécies. Elas atribuíram a Carapa guianensis maior rendimento, provavelmente devido ao menor esforço de coleta das sementes. Foram identificadas diferenças no procedimento de extração em todas as etapas, o que provavelmente é a causa do rendimento variado. $\mathrm{O}$ tempo de armazenamento das sementes antes e depois do cozimento foi identificado como diferença importante. Verificou-se a necessidade de uma orientação, em primeiro lugar, sobre o acondicionamento adequado do óleo, para manter as propriedades físicas e químicas por mais tempo. Necessita-se também procurar um maior aproveitamento dos resíduos gerados durante a extração do óleo de andiroba. Observaram-se pequenas mudanças no procedimento durante a última década: em 1992, as extratoras no município de Manacapuru utilizaram ainda pilão para preparar a massa e folhas de bananeira para forrar o ambiente do repouso das sementes. Em 2004, as folhas foram, substituídas por sacos de estopa de nylon e a massa foi amassada com as mãos.

$\mathrm{O}$ isolamento no interior do Amazonas e a falta de organização social nas comunidades facilitam e perpetuam a figura do atravessador, devido à dificuldade em escoar a produção. A conscientização do valor dos produtos naturais da Amazônia foi mais desenvolvida em Silves, embora algumas extratoras tenham lamentado que o conhecimento esteja se perdendo, pois conhecem comunidades mais afastadas, com grande produção de sementes de andiroba, porém ninguém da comunidade sabe extrair o óleo.

\section{AGRADECIMENTOS:}

Nós agradecemos as extratoras de Manacapuru, Anamã e Silves que contribuíram com a pesquisa. A Avive pelo apoio logístico em Silves e a Maria Elisabeth Assis Elias pela ajuda 
na pesquisa de campo. Este estudo foi apoiado pelo CNPq e FAPEAM.

\section{BIBLIOGRAFIA CITADA}

Aublet, F. 1977. Histoire des plantes de la Guiane Française texte. Reimpressão do original publicado em 1775. J.Cramer: Vaduz, Lichtenstein. Vol.1. 32-34p.

Clay, J.W; Sampaio, P.T.B.; Clement, C.R. 2000. Biodiversidade amazônica: exemplos e estratégias de utilização. $1^{\circ}$ ed. Manaus: Programa de Desenvolvimento Empresarial e Tecnológico. 409pp.

Ferraz, I.D.K; Camargo, J.L.C.; Sampaio, P.T.B. 2002. Sementes e Plântulas de andiroba (Carapa guianensis Aubl. e Carapa procera D.C.): Aspectos botânicos, ecológicos e tecnológicos. Acta Amazonica, 32(4): 647-661.

Gonçalves, V.A. 2001. Levantamento de mercado de produtos florestais não-madeireiros. Santarém: IBAMA- ProManejo. 65pp.

Grenand, P; Moretti, C. ; Jacquemin, H. 1987. Pharmacopées traditionnelles en Guyane. Guyane Française. Collection Mémoires 108. Edition de L'Orstom. 569pp.

McHargue, L.A.; Harstshorn, G.S. 1983. Seed and seedling ecology of Carapa guianensis. Turrialba, 33(4): 399-404.
Mendonça, A.P.; Ferraz, I.D.K. 2006. Efeito do dessecamento de sementes de andiroba (Carapa procera D.C. e Carapa guianensis Aubl.) sobre o rendimento do óleo pelo método extração tradicional no Estado do Amazonas. Anais do $3^{\circ}$ Congresso Brasileiro de Plantas Oleaginosas, Óleos, Gorduras e Biodiesel - “Biodiesel: Evolução tecnológica e qualidade”. Lavras: UFLA. p. 722-726.

Pennington, R.D.; Stules, B.T.; Taylor, D.A.H. 1981. Meliaceae. Flora Neotropica, 28:406-419.

Pesce, C. 1941. Oleaginosas da Amazônia. Oficinas gráficas da Revista Veterinária, Belém, PA. p. 66-69.

Shanley, P; Cymers, M.; Galvão, J. 1998. Frutiferas da mata na vida amazônica. Belém, PA. p. 87-90.

Silva, M.A.R. 2004. Biodiversidade Amazônica - As possibilidades da andiroba. Disponível em: www.Bioflorestal.com.br/andiroba. htm. Acesso em: 15/04/2004.

Souza, N.N; Silva, A.F.C.; Martins, F.S.; Ferreira, G.S.; Ramos, F.M.; Pereira, R.O. 2003. Plantas medicinais: etnobotanica na várzea do Mamirauá. Manaus: Ed. Rocha, S.F.R; Scarda, F.M. SEBRAE. 218pp.

Recebido em 06/10/2006

Aceito em 05/07/2007 